\title{
Technical Note: Bias correcting climate model simulated daily temperature extremes with quantile mapping
}

\author{
B. Thrasher ${ }^{1,2}$, E. P. Maurer ${ }^{3}$, C. McKellar $^{4}$, and P. B. Duffy ${ }^{5}$ \\ ${ }^{1}$ Climate Analytics Group, Palo Alto, CA 94303, USA \\ ${ }^{2}$ Climate Central, Princeton, NJ 08542, USA \\ ${ }^{3}$ Santa Clara University, Civil Engineering Dept., Santa Clara, California, 95053-0563, USA \\ ${ }^{4}$ San Jose State University, Dept. of Meteorology and Climate Science, San Jose, CA 95126, USA \\ ${ }^{5}$ Lawrence Livermore National Laboratory, Livermore, CA 94550, USA
}

Correspondence to: B. Thrasher (bridget@ climateanalyticsgroup.org)

Received: 27 March 2012 - Published in Hydrol. Earth Syst. Sci. Discuss.: 25 April 2012

Revised: 16 August 2012 - Accepted: 20 August 2012 - Published: 17 September 2012

\begin{abstract}
When applying a quantile mapping-based bias correction to daily temperature extremes simulated by a global climate model (GCM), the transformed values of maximum and minimum temperatures are changed, and the diurnal temperature range (DTR) can become physically unrealistic. While causes are not thoroughly explored, there is a strong relationship between GCM biases in snow albedo feedback during snowmelt and bias correction resulting in unrealistic DTR values. We propose a technique to bias correct DTR, based on comparing observations and GCM historic simulations, and combine that with either bias correcting daily maximum temperatures and calculating daily minimum temperatures or vice versa. By basing the bias correction on a base period of 1961-1980 and validating it during a test period of 1981-1999, we show that bias correcting DTR and maximum daily temperature can produce more accurate estimations of daily temperature extremes while avoiding the pathological cases of unrealistic DTR values.
\end{abstract}

\section{Introduction}

While monthly, seasonal, and annual changes in climate have the potential to affect ecosystems and human development (e.g., Fowler and Kilsby, 2003; Palmer and Raisanen, 2002; Schneider et al., 2007), there has been an increasing interest in the effect of shorter-term extreme events (Christensen et al., 2007; IPCC, 2011). These events can cause billions of dollars (USD) in damages in hours or days (Bouwer and
Vellinga, 2003), and changes in their magnitude and/or frequency are projected to increase the risk of amplified damages in future decades (Easterling et al., 2000).

To assess regional changes in daily extreme rainfall and temperature, global climate model (GCM) output must be downscaled to a more regionally appropriate scale. The many methods to achieve this can be broadly classified as dynamical, which uses a fine-scale climate model to interpolate GCM signals, and statistical, which uses historically derived statistical relationships between GCM-scale and finescale features to estimate regional climate (Christensen et al., 2007). In either case, before any downscaled data can be ingested into a model to estimate specific impacts of climate change, some adjustment to account for the GCM biases must be included, since at least some of the bias is systematic, being induced by factors such as inadequate terrain resolution in the GCM (Haerter et al., 2011).

We focus here on a common form of bias correction, namely quantile mapping (Panofsky and Brier, 1968; Wood et al., 2002). The quantile mapping approach has the benefit of accounting for GCM biases in all statistical moments, though, like all statistical downscaling approaches, it is assumed that biases relative to historic observations will be constant during the projections. While this quantile mapping approach has been used extensively for downscaling monthly average precipitation and temperature (Hayhoe et al., 2008; Maurer and Duffy, 2005; Wood et al., 2004), its adaptation to daily data is relatively new (Abatzoglou and Brown, 2012; Maurer et al., 2010). When maximum daily 

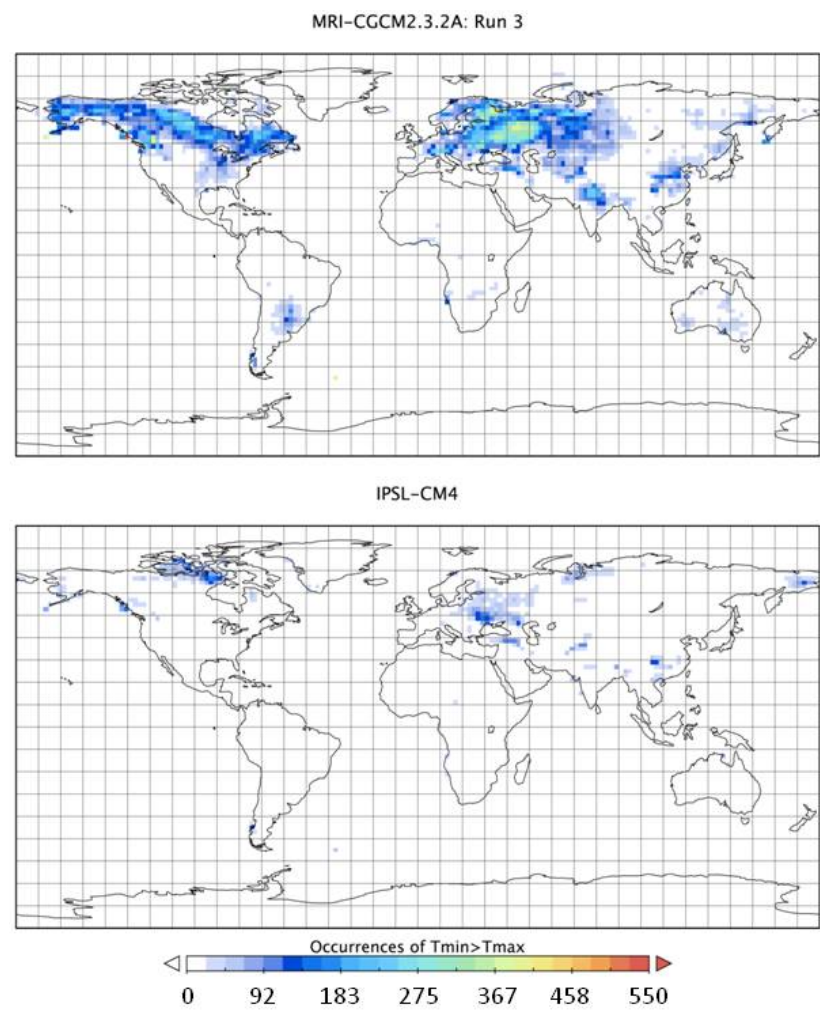

Fig. 1. For Case 1, the total number of occurrences for the validation period of 1981-1999 where $T_{\min }>T_{\max }$ after BC. Results for two GCM simulations are shown: a high number of occurrences (upper panel) and a low number of occurrences (lower panel).

temperature $\left(T_{\max }\right)$ and minimum daily temperature $\left(T_{\min }\right)$ are adjusted with quantile-mapping bias correction (hereinafter referred to as BC), the bias correction can modify the diurnal temperature range (DTR) and in some instances can result in the relationship between $T_{\max }$ and $T_{\min }$ being physically unrealistic. In this study, we compare the different alternatives to (1) minimize the error in the bias-corrected $T_{\max }$ and $T_{\min }$ values, and (2) reduce the frequency of cases where $T_{\max }$ and $T_{\min }$ are reversed in the BC process. We examine the ability to minimize these instances by instead applying the BC to diurnal temperature range (DTR) and either $T_{\min }$ or $T_{\max }$, where the remaining variable is derived by adding or subtracting the DTR as appropriate. In this way GCMsimulated trends in DTR, $T_{\min }$ and $T_{\max }$ can be retained without the need for ad hoc adjustments.

\section{Methods and data}

Table 1 lists the $17 \mathrm{GCM}$ simulations from which daily $T_{\max }$ and $T_{\min }$ values were obtained for the 1961-1999 period. These GCM simulations were archived as part of the World Climate Research Programme's (WCRP's) Coupled Model Intercomparison Project phase 3 (CMIP3)

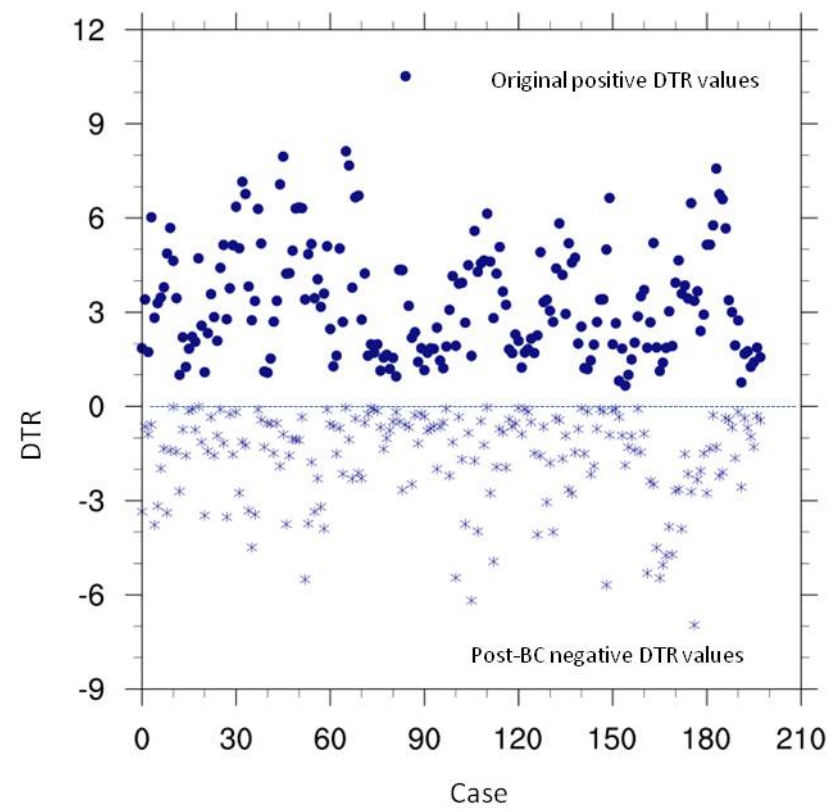

Fig. 2. Cases where $T_{\min }>T_{\max }$ at the grid cell at $57^{\circ} \mathrm{N}, 43^{\circ} \mathrm{E}$, during 1980-1989 for GCM run MRI Run 3.

multi-model dataset effort (Meehl et al., 2007). GCM output was interpolated onto a common 2-degree grid to enable intercomparison and summaries across GCMs. For an observational baseline, a 0.5 -degree daily global gridded dataset (Adam and Lettenmaier, 2003; Maurer et al., 2009) was aggregated to the same 2-degree grid spacing. DTR was calculated for each day in the 39-yr GCM simulations, as well as for the gridded observations, as the difference between $T_{\max }$ and $T_{\min }$.

The BC approach used here is essentially that of Maurer et al. (2010), but, rather than being applied to daily average temperatures, it is applied to $T_{\max }, T_{\min }$, or DTR independently. In summary, the BC uses a base period where both daily observations and daily GCM-simulated values are available. For each day of the year, a moving window of \pm 15 days is used to select all candidate days representative of the date, and all of these candidate days are sorted and ranked to produce for each calendar day two cumulative distribution functions (CDFs): one for observations and one for the GCM. For this study, we used 1961-1980 as the base period for which the BC relationships were derived. Thus for any calendar date, there would be 31 days in the moving window and $20 \mathrm{yr}$ in the base period, resulting in 620 points to define the $\mathrm{CDF}$ for each variable. A bias-corrected value for a GCM-simulated daily value is retrieved by using the $\mathrm{CDF}$ for the GCM to determine the quantile associated with the value, and then drawing the observed value from that same day's CDF for the same quantile. For example, a median $T_{\max }$ value for 15 February in the GCM output will be transformed into the median $T_{\max }$ value in the observations 


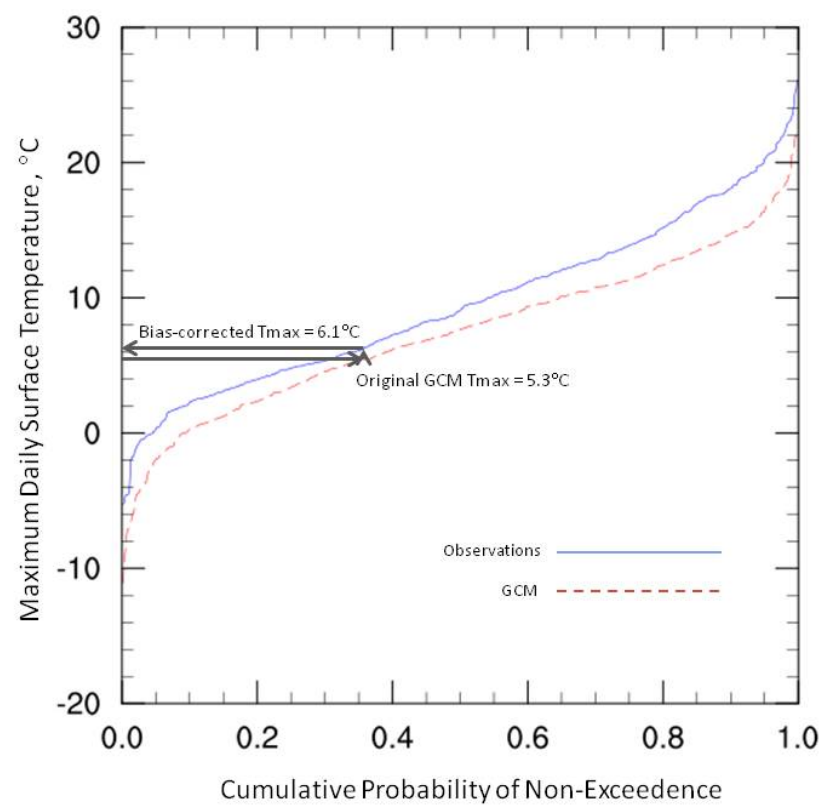

Fig. 3. CDFs for maximum daily temperature based on the period 1961-1980 for observations and MRI Run 3. Arrows illustrate the quantile mapping for the daily $T_{\max }$ value for 17 April 1983.

for 15 February, where the median value is that daily value exceeded $50 \%$ of the time in the set of 620 days defining the CDFs for 15 February.

We perform three variations of daily temperature $\mathrm{BC}$ :

- Case 1: BC performed for $T_{\max }$ and $T_{\min }$;

- Case 2: BC performed for $T_{\min }$ and DTR, with $T_{\max }$ calculated as $T_{\min }+$ DTR;

- Case 3: BC performed for $T_{\max }$ and DTR, with $T_{\min }$ calculated as $T_{\max }-$ DTR.

Case 1 is the default case, with shortcomings discussed above. Cases 2 and 3 are evaluated by comparing the rootmean-square error (RMSE) across all days and grid cells for global land areas, where the RMSE is calculated for the derived variable (i.e., for Case 2 RMSE for $T_{\max }$ is assessed, and for Case $3 \mathrm{RMSE}$ for $T_{\min }$ is assessed). The three cases are assessed for the validation period of 1981-1999.

\section{Results and discussion}

The results for Case 1 are shown in Fig. 1. Despite the wide variability in the number of cases where $T_{\min }>T_{\max }$ after BC of the GCM output, Fig. 1 shows, for extreme high and low cases, that these tend to occur predominantly at high latitudes (and this is generally the case for all of the GCM simulations used in this study). For these high latitude regions, the GCMs have biases in mean and/or variability that tend to produce more occurrences of $T_{\min }>T_{\max }$ when adjusted

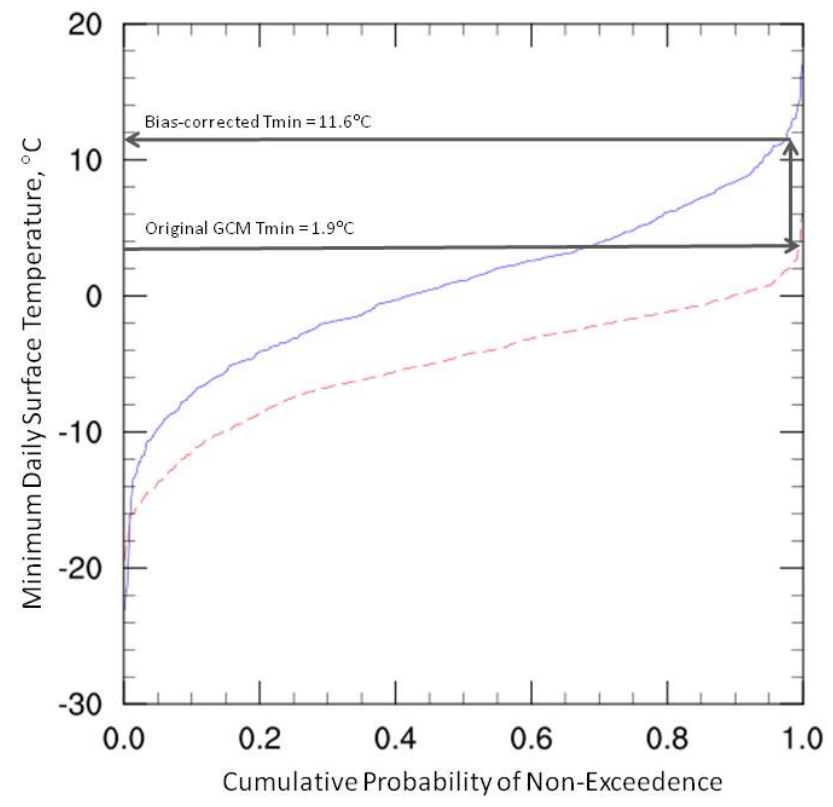

Fig. 4. Same as Fig. 3, but for minimum daily temperatures.

Table 1. GCMs and run numbers included in this study.

\begin{tabular}{ll}
\hline & Simulation \\
\hline 1 & CCCMA-CGCM3-1: Run 1 \\
2 & CCCMA-CGCM3-1: Run 2 \\
3 & CCCMA-CGCM3-1: Run 3 \\
4 & CNRM-CM3 \\
5 & GFDL-CM2-0 \\
6 & GFDL-CM2-1 \\
7 & IPSL-CM4 \\
8 & MIROC3-2-MEDRES: Run 1 \\
9 & MIROC3-2-MEDRES: Run 2 \\
10 & MIUB-ECHO-G: Run 1 \\
11 & MIUB-ECHO-G: Run 2 \\
12 & MIUB-ECHO-G: Run 3 \\
13 & MPI-ECHAM5 \\
14 & MRI-CGCM2.3.2A: Run 1 \\
15 & MRI-CGCM2.3.2A: Run 2 \\
16 & MRI-CGCM2.3.2A: Run 3 \\
17 & MRI-CGCM2.3.2A: Run 4 \\
\hline
\end{tabular}

through BC. How this can occur is demonstrated here using a single grid cell located at latitude $57^{\circ} \mathrm{N}$ longitude $43^{\circ} \mathrm{E}$ (northeast of Moscow, Russia) from MRI Run 3 (Run 13 in Table 1). For the decade of the 1980s, 3653 days in total, there were 198 cases where the bias correction resulted in $T_{\min }>T_{\max }$, which are depicted in Fig. 2. For this decade, the DTR has a mean of $8.7^{\circ} \mathrm{C}$ and a standard deviation of $5.2^{\circ} \mathrm{C}$. For the 198 cases in Fig. 2, the mean DTR is $3.4^{\circ} \mathrm{C}$, standard deviation $1.8^{\circ} \mathrm{C}$. A two-sample t-test at $\alpha=0.05$ shows the difference between these means to be statistically significant with very high confidence $(p<0.0001)$, demonstrating how 


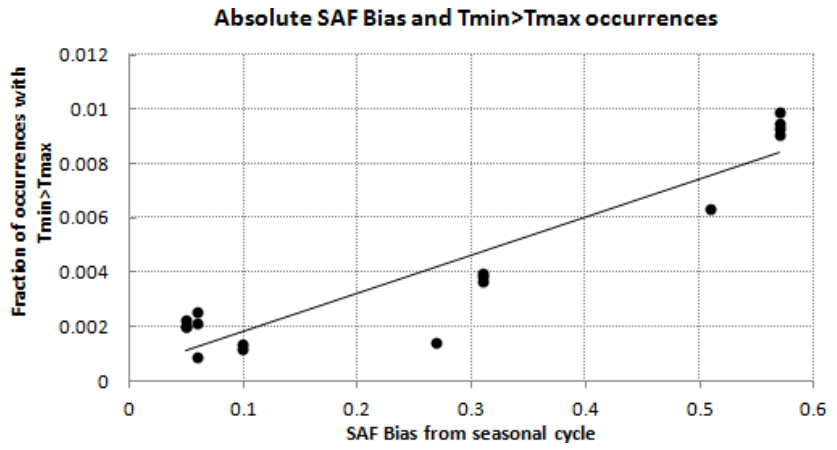

Fig. 5. Fraction of occurrences across all (land area) GCM grid cells and all March-May days in the validation period of 1981-1999 versus the snow albedo feedback error, calculated from Hall and $\mathrm{Qu}$ (2006) based on GCM-simulated seasonal cycle between April and May.

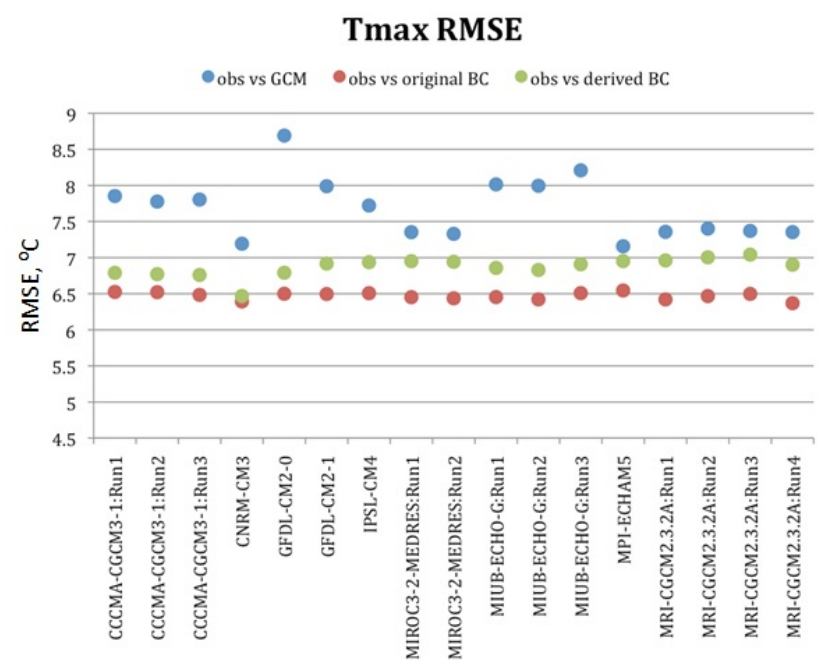

Fig. 6. The RMSE $\left({ }^{\circ} \mathrm{C}\right)$ between gridded observations and three versions of $T_{\max }$ for $17 \mathrm{GCM}$ simulations: regridded daily GCM $T_{\max }$ (blue), bias-corrected daily GCM $T_{\max }$ (red), and daily $T_{\max }$ derived from bias-corrected DTR and $T_{\min }$ (green, Case 2).

cases with small DTR, relative to the GCM bias, are more prone to having this issue.

The method by which this occurs is illustrated for the same grid cell and run used above for one of the cases in Fig. 2, corresponding to 17 April 1983. The CDF for maximum temperature is constructed as described above, using a window of \pm 15 days around 17 April. Using the period 1961-1980 as the climatological period, 620 days are used to define the CDFs. As shown in Fig. 3, the GCM underpredicts the daily $T_{\max }$ value throughout the distribution. Figure 4 shows the same as Fig. 3, but for $T_{\min }$, which the GCM also underestimates, but by a much wider margin than for $T_{\max }$. The quantile mapping is illustrated in Figs. 3 and 4, transforming the raw GCM $T_{\max }$ and $T_{\min }$ of $5.3{ }^{\circ} \mathrm{C}$ and $1.9^{\circ} \mathrm{C}$, respectively,

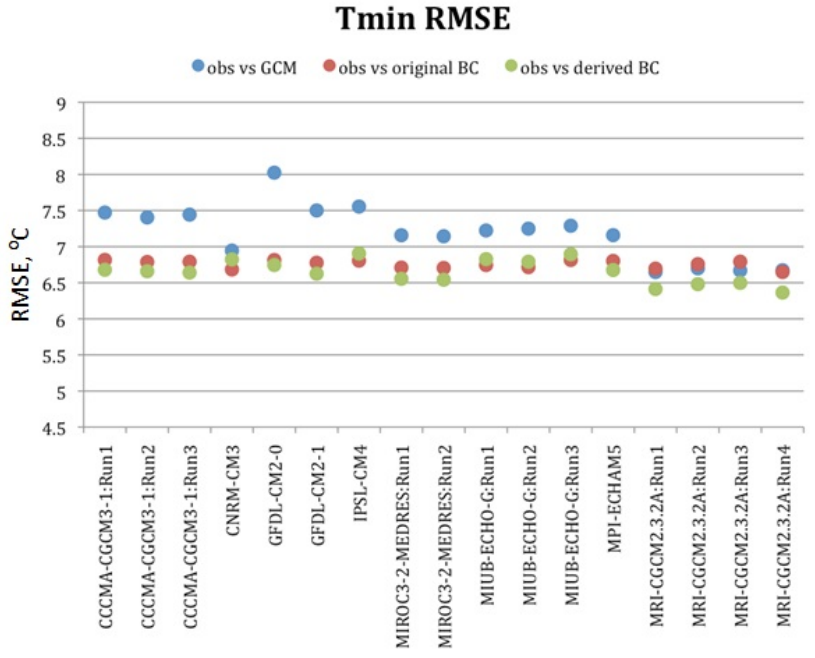

Fig. 7. The RMSE $\left({ }^{\circ} \mathrm{C}\right)$ between gridded observations and three versions of $T_{\min }$ for $17 \mathrm{GCM}$ simulations: regridded daily GCM $T_{\min }$ (blue), bias-corrected daily GCM $T_{\min }$ (red), and daily $T_{\min }$ derived from bias-corrected DTR and $T_{\max }$ (green, Case 3 ).

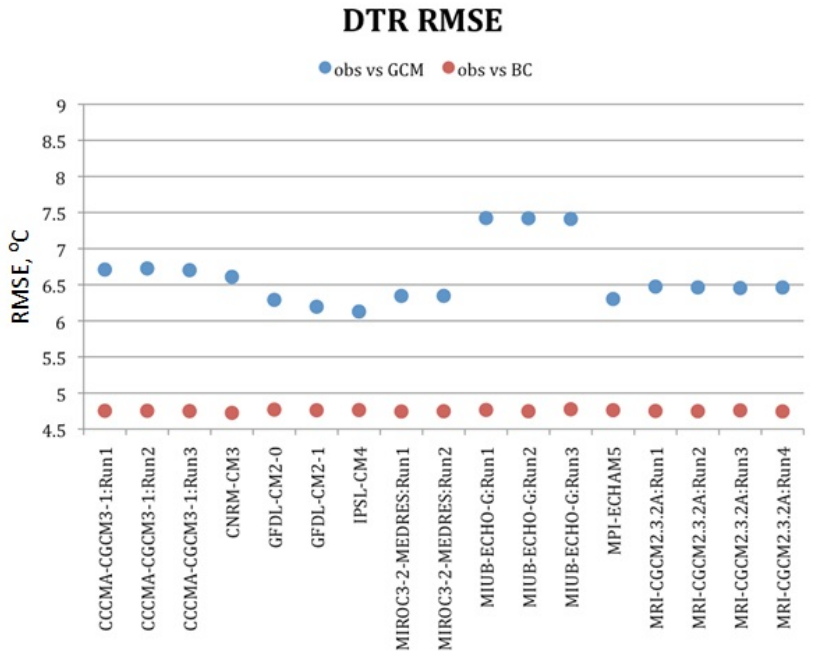

Fig. 8. RMSE $\left({ }^{\circ} \mathrm{C}\right)$ between gridded observations and two versions of DTR for 17 GCM simulations: regridded daily GCM DTR (blue) and bias-corrected daily GCM DTR (red).

to bias-corrected values of $6.1^{\circ} \mathrm{C}$ and $11.6^{\circ} \mathrm{C}$, respectively, producing $T_{\min }>T_{\max }$ and a physically impossible DTR.

For most GCM simulations, the greatest number of cases occurs in March-May, or during the Northern Hemisphere snowmelt season. Hall and Qu (2006) identified GCM biases in the representation of melt season snow albedo in the Northern Hemisphere as a major factor in the variability in GCM-simulated climate sensitivity. Climate model errors in simulating snow would have a direct impact on DTR, with increased DTR being related to increased snow melt (Karl et al., 1993), or conversely, increased snow presence 
being related to a decreased DTR, especially early and late in the snow season, due largely to the large decline in $T_{\max }$ when snow is present due to increased albedo (Leathers et al., 1995). While a thorough investigation of this is ongoing, the GCM error in snow albedo feedback (from the abscissa of Fig. 3 in Hall and Qu, 2006) and the frequency of $T_{\min }>T_{\max }$ occurrences in this study are highly significantly correlated (Pearson $r^{2}=0.87$; Fig. 5), illustrating a strong relation between GCM biases in snow albedo and the biases in daily surface air temperatures that cause more $T_{\min }>T_{\max }$ occurrences during BC, though causality has not yet been determined. It should be noted that, even in the extreme case over Eastern Europe for the worst case of the GCMs used here, fewer than 400 occurrences are observed in the $19 \mathrm{yr}$ validation period, indicating less than $6 \%$ of days having $T_{\min }>T_{\max }$, with most of global land areas and GCM simulations exhibiting far less than this. On average for all GCM simulations, $T_{\min }>T_{\max }$ occurs approximately $0.25 \%$ of the time.

The two approaches conducted in this study to remedy the occurrence of $T_{\min }>T_{\max }$ following the BC process, Cases 2 and 3 , are compared to determine the preferable alternative. Figure 6 shows the results for Case 2, where the "obs vs. original BC" RMSE refers to $T_{\max }$ produced as in Case 1, and the "obs vs. derived BC" being that calculated as described above for Case 2. First, both cases of bias correction improve the original GCM output, as is evident by the RMSE for both Case 1 and Case 2 being lower than for the "obs vs. GCM" points. The RMSE shown in Fig. 6 for Case 2 is higher than for Case 1, which shows that, for all GCM simulations, the approach of Case 2, while eliminating occurrences of $T_{\min }>T_{\max }$, deteriorates the estimation of $T_{\max }$ in the $\mathrm{BC}$ process.

Figure 7 shows similar results to Fig. 6 but for Case 3. In this alternative, "obs vs. original $\mathrm{BC}$ " refers to the $\mathrm{BC} T_{\min }$ as in Case 1, and "obs vs. derived BC" is that calculated according to the description of Case 3 above. As with Case 2 (Fig. 6) for most GCMs, either approach to BC (Case 1 or Case 3 in Fig. 7) results in decreased RMSE, thus producing $T_{\min }$ values that bear greater resemblance to observations. In contrast to Case 2, the $T_{\min }$ values derived in Case 3 show reduced RMSE for 12 of the $17 \mathrm{GCM}$ simulations, indicating that this alternative not only removes the possibility of $T_{\min }>T_{\max }$ in the BC process, but results in an improved estimation of $T_{\min }$ on average.

That GCM-simulated $T_{\max }$ appears more capable of benefiting from a quantile mapping bias correction than $T_{\min }$ suggests that the biases, relative to observations, exhibited for $T_{\max }$ may be more systematic than those for $T_{\min }$. While a mechanism explaining this has neither been expressed in the literature, to the authors' knowledge, nor been proposed here, the consistency with other research results (Maurer et al., 2012) is encouraging as a topic for future efforts.

Finally, while Case 3 appears to be the best solution of the alternatives assessed in this study, since applying BC to DTR is a new application, we verified that DTR is not degraded in the BC process (Fig. 8). The RMSE for DTR relative to observations (for the 1981-1999 validation period) is reduced on average $28 \%$ after BC. Compared to bias correcting $T_{\max }$ and $T_{\min }$ independently (i.e., Case 1), bias correcting $T_{\max }$ and DTR and deriving $T_{\min }$ as $T_{\max }$-DTR (Case 3 ) results in reduced RMSE of $T_{\max }$ (by $15 \%$ on average) and $T_{\min }$ (by $7 \%$ on average), and improves DTR as well.

\section{Conclusions}

We evaluated the potential to improve the quantile mapping bias correction approach when applied to daily GCM output of maximum and minimum temperatures. A direct bias correction of both $T_{\max }$ and $T_{\min }$ results in some cases where the unrealistic occurrence of $T_{\min }>T_{\max }$ appears. To remedy this, we first derive the diurnal temperature range for each day, and then apply the bias correction to DTR and either $T_{\max }$ or $T_{\min }$, calculating the remaining variable.

We find that bias correcting daily DTR and $T_{\max }$ and calculating $T_{\min }$ as $T_{\max }$-DTR eliminates the occurrence of $T_{\min }>T_{\max }$ and in general improves the estimation of $T_{\min }$ compared to bias correcting $T_{\min }$ directly. This approach will be further assessed and implemented in future applications of quantile mapping bias correction of daily GCM temperature output.

Acknowledgements. Funding for this work was provided by the U.S. Army Corps of Engineers under grant W912HQ-IWRCLIMATE. We acknowledge the modeling groups, the Program for Climate Model Diagnosis and Intercomparison (PCMDI) and the WCRP's Working Group on Coupled Modelling (WGCM) for their roles in making available the WCRP CMIP3 multi-model dataset. Support of this dataset is provided by the Office of Science, US Department of Energy.

Edited by: B. Schaefli

\section{References}

Abatzoglou, J. T. and Brown, T. J.: A comparison of statistical downscaling methods suited for wildfire applications, Int. J. Climatol., 32, 772-780, doi:10.1002/joc.2312, 2012.

Adam, J. C. and Lettenmaier, D. P.: Adjustment of global gridded precipitation for systematic bias, J. Geophys Res., 108, 1-14, 2003.

Bouwer, L. and Vellinga, P.: Changing climate and increasing costs - Implications for liability and insurance Climatic Change: Implications for the Hydrological Cycle and for Water Management, edited by: Beniston, M., Advances in Global Change Research, Springer Netherlands, 429-444, 2003.

Christensen, J. H., Hewitson, B., Busuioc, A., Chen, A., Gao, X., Held, I., Jones, R., Kolli, R. K., Kwon, W.-T., Laprise, R., Magaña Rueda, V., Mearns, L., Menéndez, C. G., Räisänen, J., Rinke, A., Sarr, A., and Whetton, P.: Regional climate projec- 
tions, in: Climate Change 2007: The Physical Science Basis, Contribution of Working Group I to the Fourth Assessment Report of the Intergovernmental Panel on Climate Change edited by: Solomon, S., Qin, D., Manning, M., Chen, Z., Marquis, M., Averyt, K. B., Tignor, M., and Miller, H. L., Cambridge University Press, Cambridge, United Kingdom and New York, NY, USA, 2007.

Easterling, D. R., Meehl, G. A., Parmesan, C., Changnon, S. A., Karl, T. R., and Mearns, L. O.: Climate extremes: Observations, modeling, and impacts, Science, 289, 2068-2074, 2000.

Fowler, H. J. and Kilsby, C. G.: Implications of changes in seasonal and annual extreme rainfall, Geophys. Res. Lett., 30, 1720, doi:10.1029/2003g1017327, 2003.

Haerter, J. O., Hagemann, S., Moseley, C., and Piani, C.: Climate model bias correction and the role of timescales, Hydrol. Earth Syst. Sci., 15, 1065-1079, doi:10.5194/hess-15-10652011, 2011.

Hall, A. and Qu, X.: Using the current seasonal cycle to constrain snow albedo feedback in future climate change, Geophys. Res. Lett., 33, L03502, doi:10.1029/2005g1025127, 2006.

Hayhoe, K., Wake, C., Anderson, B., Liang, X.-Z., Maurer, E., Zhu, J., Bradbury, J., DeGaetano, A., Stoner, A., and Wuebbles, D.: Regional climate change projections for the Northeast USA, Mitigation and Adaptation Strategies for Global Change, 13, 425436, doi:10.1007/s11027-007-9133-2, 2008.

IPCC: Intergovernmental Panel on Climate Change Special Report on Managing the Risks of Extreme Events and Disasters to Advance Climate Change Adaptation, Summary for Policymakers, edited by: Field, C. B., Barros, V., Stocker, T. F., Qin, D., Dokken, D., Ebi, K. L., Mastrandrea, M. D., Mach, K. J., Plattner, G.-K., Allen, S. K., Tignor, M., and Midgley, P. M., Cambridge University Press, Cambridge, United Kingdom and New York, NY, USA, 2011.

Karl, T. R., Knight, R. W., Gallo, K. P., Peterson, T. C., Jones, P. D., Kukla, G., Plummer, N., Razuvayev, V., Lindseay, J., and Charlson, R. J.: A New Perspective on Recent Global Warming: Asymmetric Trends of Daily Maximum and Minimum Temperature, B. Am. Meteorol. Soc., 74, 1007-1023, doi:10.1175/15200477(1993)074<1007:anporg>2.0.co;2, 1993.

Leathers, D. J., Ellis, A. W., and Robinson, D. A.: Characteristics of Temperature Depressions Associated with Snow Cover across the Northeast United States, J. Appl. Meteorol., 34, 381-390, doi:10.1175/1520-0450-34.2.381, 1995.
Maurer, E. P. and Duffy, P. B.: Uncertainty in projections of streamflow changes due to climate change in California, Geophys. Res. Lett., 32, L03704, doi:10.1029/2004GL021462, 2005.

Maurer, E. P., Adam, J. C., and Wood, A. W.: Climate model based consensus on the hydrologic impacts of climate change to the Rio Lempa basin of Central America, Hydrol. Earth Syst. Sci., 13, 183-194, doi:10.5194/hess-13-183-2009, 2009.

Maurer, E. P., Hidalgo, H. G., Das, T., Dettinger, M. D., and Cayan, D. R.: The utility of daily large-scale climate data in the assessment of climate change impacts on daily streamflow in California, Hydrol. Earth Syst. Sci., 14, 1125-1138, doi:10.5194/hess14-1125-2010, 2010.

Maurer, E. P., Das, T., and Cayan, D. R.: Systematic errors in climate model daily precipitation and temperature output: implications for bias correction, J. Geophys. Res., in review, 2012.

Meehl, G. A., Covey, C., Delworth, T., Latif, M., McAvaney, B., Mitchell, J. F. B., Stouffer, R. J., and Taylor, K. E.: The WCRP CMIP3 multimodel dataset: A new era in climate change research, B. Am. Meteorol. Soc., 88, 1383-1394, 2007.

Palmer, T. N. and Raisanen, J.: Quantifying the risk of extreme seasonal precipitation events in a changing climate, Nature, 415, 512-514, 2002.

Panofsky, H. A. and Brier, G. W.: Some Applications of Statistics to Meteorology, The Pennsylvania State University, University Park, PA, USA, 224 pp., 1968.

Schneider, S. H., Semenov, S., Patwardhan, A., Burton, I., Magadza, C. H. D., Oppenheimer, M., Pittock, A. B., Rahman, A., Smith, J. B., Suarez, A., and Yamin, F.: Assessing key vulnerabilities and the risk from climate change, in: Climate Change 2007: Impacts, Adaptation and Vulnerability. Contribution of Working Group II to the Fourth Assessment Report of the Intergovernmental Panel on Climate Change, edited by: Parry, M., Canziani, O., Palutikof, J., van der Linden, P., and Hanson, C., Cambridge University Press, Cambridge, UK, 779-810, 2007.

Wood, A. W., Maurer, E. P., Kumar, A., and Lettenmaier, D. P.: Long-range experimental hydrologic forecasting for the eastern United States, J. Geophys Res., 107, 4429, doi:10.1029/2001JD000659, 2002.

Wood, A. W., Leung, L. R., Sridhar, V., and Lettenmaier, D. P.: Hydrologic implications of dynamical and statistical approaches to downscaling climate model outputs, Climatic Change, 62, 189216, 2004. 